from a used ladle; the keys are knocked out of the plate bolts; and the nozzle plate is pried off.

A short bar, having a right angle hook on the working end, is inserted into the nozzle hole to break out the old nozzle. After the old nozzle is completely removed, the inside surface of the opening is cleaned out and any rough places are smeared with mud by hand.

The new nozzle, smeared all over with mud, is inserted into the ladle. This mud is made by grinding 24 parts white plastic clay with 5 parts

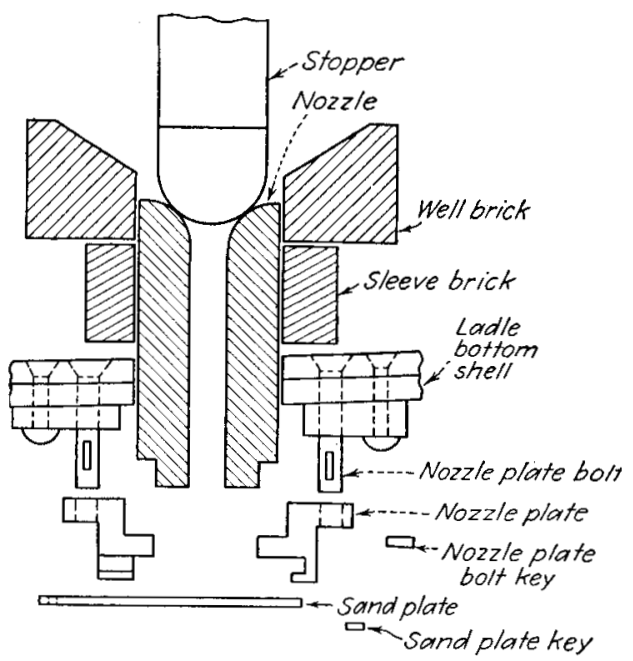

Cross section of nozzle arrangement showing stopper and nozzle in position.

graphite, and mixing to a consistency of soft putty. The nozzle, after being covered with about 1 in. of mud, is inserted into the nozzle opening in the ladle.

After the mudded nozzle has been pushed half way in by hand, the nozzle plate is placed on the end of the nozzle. The holes in the plate are lined up with the bolts in the bottom of the ladle, and the plate is tapped simultaneously on either side to drive it into final position. The small keys are driven into the slots in the nozzle bolts to secure the plate fast to the bottom of the ladle. To insure against leaks through the nozzle, the end of the nozzle hole is smeared with mud before inserting the sand plate.

The sand plate, inserted endwise through the three small lugs on the base of the nozzle plate, is keyed into position by driving wedge pins between the lugs and the plate.

Just prior to setting the stopper, a small scoop of white sand is poured into the well from the edge of the ladle. Just enough is used to fill the hole in the nozzle and form a light cushion for the stopper head. The sand prevents steel from entering the nozzle hole before the heat is opened up.

The advantages of this method of changing nozzles are several. Ladles need be out of service only 12 to $15 \mathrm{~min}$ between pours to change nozzles. Furnace time often can be saved by tapping into a hot ladle instead of recarburizing the heat with hot metal and holding it in the furnace to gain temperature. A light ladle skull may be melted out by using the hot ladle immediately on the next heat.

No work is required inside hot ladles. Fewer ladles are required, because of the short delay time between heats. Hazards of climbing in and out of hot ladles are eliminated.

In the 20 years this method of setting nozzles has been in use at National Works, cases have been rare where trouble was encountered from steel breaking out around the nozzle.

\title{
Aluminum Foil-Laminate Gasket
}

A NOVEL and interesting gasket material has been developed, based on an aluminum-foil laminate bonded with a special synthetic resin, as reported in an article in Light Metals for February, 1950. According to the purpose for which the gasket is to be used, the thickness of the individual foils employed will vary from 0.00394 to 0.0005 in. The total thickness of the laminated mass may vary at will, but, for the majority of purposes, $1 / 32$ in. appears to be most effective. Unless a different thickness is specified, all gaskets are cut from this gage.

The properties of the foil laminate are such that not only may it readily be cut to shape with shears or tinsnips, but, even in the mass production of particular gaskets, it required only the simplest and cheapest of tools.

In use, its capacity for plastic deformation is such that it will readily take up all surface forms against which it is bolted, including machining marks. A gas-tight seal is thus assured. In this regard, the plastic adhesive also plays a part, for, under pressure, some slight exudation occurs at the cut edges and, under the influence of heat, hardening of the resin occurs. This bonds the edges together and fur- thermore seals the laminate against penetration by gas under pressure. A further valuable service performed by the synthetic-resin bond occurs in those situations where chemical attack of the outer surface of the foil may occur, as, for example, in marine engines. Here, even though the outer layer of foil be entirely removed, for example, by the action of salt water, progress of attack tends largely to be inhibited by the varnish-like film adhering to the following sheet.

Plexeal aluminum-foil-laminate gaskets, made by Plexeal, Ltd., Haddenham, England, may be used for all purposes where normal gasket materials are required, on marine engines, water-cooled engines, aircooled engines, compressors, steam installations, and the like. In the case of smaller internal-combustion engines, experience appears to have shown that the use of aluminum-foil packs for the cylinder-head gasket actually promotes more efficient running, inasmuch as heat dissipation is facilitated by the presence of the mass of high-conductivity metal.

Plexeal gaskets are manufactured in standard forms, or the uncut material is obtainable in the form of sheets, measuring $18 \times 7$ in., $28 \times 9$ in., or $35 \times 9$ in. 